\title{
Mechanical properties and tribological behavior at micro and macro-scale of WC/WCN/W hierarchical multilayer coatings
}

\author{
Cesar D. Rivera-Tello, Esteban Broitman, F. J. Flores-Ruiz, O. Jimenez and M. Flores
}

\section{Linköping University Post Print}

\section{Tweet}

N.B.: When citing this work, cite the original article.

Original Publication:

Cesar D. Rivera-Tello, Esteban Broitman, F. J. Flores-Ruiz, O. Jimenez and M. Flores, Mechanical properties and tribological behavior at micro and macro-scale of WC/WCN/W hierarchical multilayer coatings, 2016, Tribology International, (101), , 194-203.

http://dx.doi.org/10.1016/j.triboint.2016.04.017

Copyright: Elsevier

http://www.elsevier.com/

Postprint available at: Linköping University Electronic Press

http://urn.kb.se/resolve?urn=urn:nbn:se:liu:diva-130367

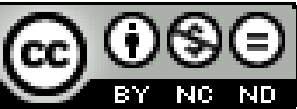




\title{
Mechanical Properties and Tribological Behavior at Micro and Macro-Scale of WC/WCN/W Hierarchical Multilayer Coatings
}

\section{César D. Rivera-Tello, ${ }^{1}$ E. Broitman, ${ }^{2}$ F. J. Flores-Ruiz, ${ }^{3,4}$ O. Jiménez, ${ }^{1}$ M. Flores ${ }^{1}$}

${ }^{1}$ Departamento de Ingeniería de Proyectos, CUCEI, Universidad de Guadalajara, Blvd. Marcelino García Barragán 1421, Olímpica, Guadalajara Jalisco México C.P. 44430

${ }^{2}$ Department of Physics, Chemistry and Biology, IFM, Linköping University, SE-581 83 Linkoping, Sweden

${ }^{3}$ Centro de Nanociencias y Nanotecnología (CNyN), Universidad Nacional Autónoma de México (UNAM), km 107 Carretera Tijuana-Ensenada, Ensenada, B. C., C.P. 22860, México

${ }^{4}$ CINVESTAV-Unidad Querétaro, Libramiento Norponiente 2000 Frac. Real de Juriquilla Santiago de Querétaro, Qro. México 76230.

\begin{abstract}
It is known that a hierarchical configuration helps to improve adhesion to the substrate and reduce the effects that generate a sharp change in a conventional multilayer coating, like interface stresses. We present a study of the mechanical properties and tribological behavior at the micro and macro scale of WC/WCN/W multilayer coatings deposited by magnetron sputtering, combining soft and hard layers with a hierarchical architecture. Variations in the number of layers and thicknesses, as well as the distribution within the coating are determinant to obtain the adequate mechanical properties in order to reduce the wear rate. It was found that the coating with high hierarchical configuration presented lower wear rates, in comparison to single layer and low hierarchical configuration coatings.
\end{abstract}

Keywords: Hierarchical multilayers; Magnetron Sputtering; Tribological behavior; Wear. 


\section{Introduction}

Over the last two decades many of the studies regarding multilayers coatings deposited by magnetron sputtering were done seeking continuous improvement of the hardness and adhesion of coatings subject to mechanical contact [1-5]. Some of the advantages of such coatings are related to their capacity to block the sliding of dislocations through the layer interfaces of the different materials and to hinder the crack propagation through the film. [6, 7]. However, interfaces with abrupt changes in mechanical properties produce a poor and deficient bonding strength between the constitutive layers, leading to embrittlement. But, if a sharp transition in the multilayer configuration is replaced by a continuous transition (hierarchical or graded multilayer), the bonding strength of the interfaces is usually improved [8]. Also, there are others related benefits to the use of graded materials as the reduction of thermal stress, stress jumps at the interface, the driving force for crack extension and the stress intensity [8]. Not all these benefits are completely explained and more studies are necessary in order to achieve a better understanding about the interaction of graded materials. Jiang Xu et al [9] showed that, in the case of MoSi 2 -based nanocomposite coatings, toughness depends strongly of a hierarchical configuration and the magnitude of the compressive residual stress within the film. Another important benefit, reported by Yu Zhang and co-workers [10], is the improvement in load bearing capacity of ceramics through hierarchical surfaces using materials with low modulus. These results might be useful to considerer in hard coatings deposited by magnetron sputtering with a hierarchical design in order to improve toughness, load bearing, and wear resistance.

Tungsten based hard coatings have many interesting applications such as space nuclear power, propulsion for heat pipes, nuclear fuel cladding and radiation shields [11], and in semiconductor substrates for microelectronics [12]. In wear applications; tungsten is used for protection of bores of large caliber tank-guns [13] and in microelectromechanical systems (MEMS), tungsten coatings are used to improve their wear resistance [12]. Transition metal carbide and/or nitride coatings have been extensively studied in recent works, due to their excellent performance as wear resistant coatings $[14,15,16]$. Tungstencarbide (WC) coatings have higher physical and mechanical properties than tungsten [16]. 
The advantage of using C-containing films is also known for reducing the friction coefficient and thus, improving wear resistance [17].

In this study we propose the use of WC, WCN and W layers grown by magnetron sputtering to design multilayers in a hierarchical configuration in order to obtain a hard coating with mechanical properties that improve the tribological behavior of CoCrMo alloy substrates.

\section{Material and methods}

\subsection{Coating Deposition and Characterization}

Two WC/WCN/W hierarchical multilayer and a WCN single-layer coatings were deposited by unbalanced reactive DC magnetron sputtering from $\mathrm{W}$ and $\mathrm{C}$ targets of 50.8 millimeters diameter in a vacuum chamber with a base pressure of less than $3.4 \times 10^{-4} \mathrm{~Pa}\left(3.4 \times 10^{-6}\right.$ mbar). Mirror polished CoCrMo coupons, of $30 \mathrm{~mm}$ diameter and $8 \mathrm{~mm}$ height, were used as substrates. Prior to deposition, the substrates were subsequently cleaned in ultrasonic baths of acetone and isopropyl alcohol during 10 min each.

The hierarchical multilayer coatings were built alternating the deposition of individual layers of WC, WCN and W. The W layers were deposited from a W target using a current of 0.4 A and 0.6 sccm of Ar gas flow at $~ 0.8 \mathrm{~Pa}$ deposition pressure. The WC layers were grown by co-deposition from $\mathrm{C}$ and $\mathrm{W}$ targets using the Ar gas flow and deposition pressure mentioned above, while the current of the $\mathrm{W}$ and $\mathrm{C}$ targets were kept at $0.4 \mathrm{~A}$ and 0.09 A respectively. For the deposition of WCN layers, Ar flow and currents of both targets remained as in the previous two layers, plus the addition of $0.4 \mathrm{sccm}$ of $\mathrm{N}_{2}$ gas flow at a deposition pressure of $\sim 0.9 \mathrm{~Pa}$. Thus, the hierarchical multilayers configuration of WC/WCN/W films was obtained interrupting the $\mathrm{N}_{2}$ flow (for WC layers) and turning off the C target (for W layers). The WCN single layer coatings were deposited according to the WCN layers parameters into the hierarchical multilayer coatings. Furthermore, during the deposition of all the coatings, the substrate holder was rotating at $8 \mathrm{rev} / \mathrm{min}$ and a substrate negative bias voltage of $-50 \mathrm{~V}$ was applied. A ceramic heater was maintained to a constant 
temperature of $200{ }^{\circ} \mathrm{C}$ during the whole process and for all the coatings. The target to substrate distance was set at $55 \mathrm{~mm}$ for both targets as it is shown in Figure 1.

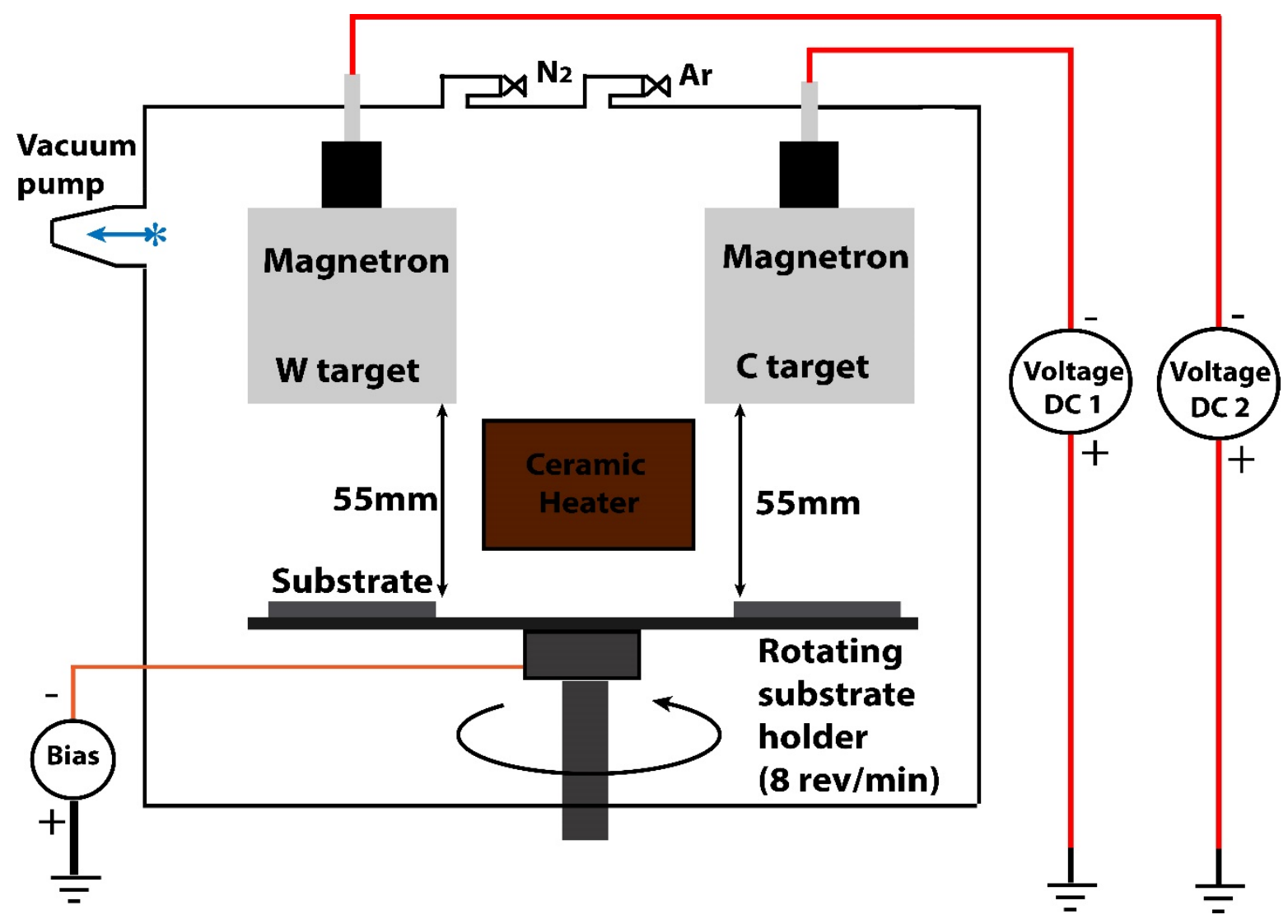

Fig. 1. Scheme of the sputtering system used for the deposition of the hierarchical multilayer and single layer coatings.

The hierarchical or graded configuration of each layer of WC/WCN/W coatings and the single-layer WCN, along with the deposition time or period size are schematically shown in Figure 2. Samples with high hierarchical configuration (High HIER) were deposited by gradually decreasing the deposition time (D. T.) until the top layer, alternating W, WCN and WC layers to generate a large number of interfaces (Figure 2a). There is a group of samples deposited with low hierarchical configuration (Low HIER) consisting of three 
thick layers of W, WCN, WC with equal thickness, followed on the top by a multilayer system of WC and WCN films $(D . T \cdot W C N=10 \mathrm{~min}, D \cdot T \cdot W C=2 \mathrm{~min})$, (Figure 2b). Single layer WCN sample consisted of a layer deposited during 140 minutes onto a W film used to enhance adhesion to the substrate (Figure 2c).

High HIER

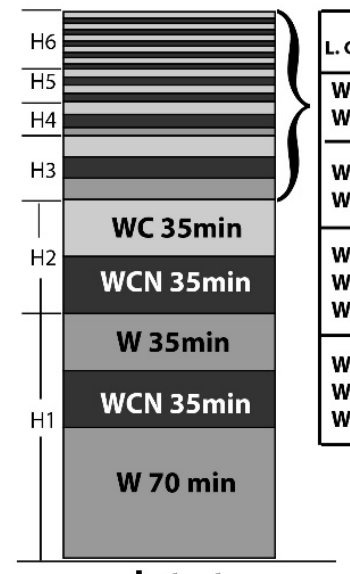

a) substrate

\begin{tabular}{|c|c|c|}
\hline L. C. & $\begin{array}{c}\mathrm{D} . \mathrm{T}_{\mathrm{in}} \\
\text { (min }\end{array}$ & Layers \\
\hline $\begin{array}{l}\text { WC } \\
\text { WCN }\end{array}$ & $\begin{array}{l}4 \\
3\end{array}$ & $\begin{array}{l}5 \\
5\end{array}$ \\
\hline $\begin{array}{l}\text { WC } \\
\text { WCN }\end{array}$ & $\begin{array}{l}5 \\
5\end{array}$ & ${ }_{2}^{2} \mathrm{H} 5$ \\
\hline $\begin{array}{l}\text { WC } \\
\text { WCN } \\
\text { W }\end{array}$ & $\begin{array}{l}8 \\
8 \\
5\end{array}$ & $\begin{array}{l}1 \\
1 \\
1\end{array}$ \\
\hline $\begin{array}{l}\text { WC } \\
\text { WCN }\end{array}$ & $\begin{array}{l}13 \\
13\end{array}$ & $\begin{array}{l}1 \\
1\end{array}$ \\
\hline
\end{tabular}

b)

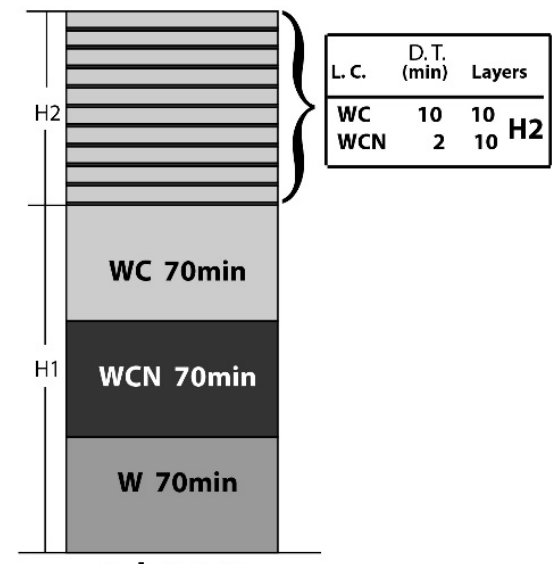

\section{Low HIER}

c)
Single-layer WCN

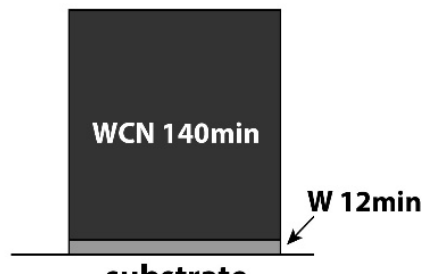

substrate

Fig. 2. Schematic diagram of the deposition time of a) high and b) low hierarchized coatings as well as c) single layer WCN. L.C (Note: L.C = layer composition, D.T = deposition time).

The cross section morphology and the thickness were measured from images of the fractured samples deposited on Si (100) substrates acquired with a FESEM Tescan MIRA 3 LMU system. The structural identification was assessed by X-ray diffraction (XRD) experiments through a Rigaku D/Max 2100 diffractometer with a $\mathrm{Cu} \mathrm{K \alpha}$ radiation at $30 \mathrm{kV}$ and $20 \mathrm{~mA}$. The $\theta-2 \theta$ range for scans was from $20^{\circ}-100^{\circ}$, in $2 \theta$ at a scan rate of $0.0263^{\circ} / \mathrm{s}$ following the Bragg-Brentano geometry.

\subsection{Mechanical and Tribological Tests}

The nano-mechanical properties and micro-tribological behavior of the coatings were determined by using a Triboindenter TI-950 from Hysitron. The hardness $(\mathrm{H})$ and the 
reduced elastic modulus (Er) were obtained from load-displacement curves by performing nine indentations at $12 \mathrm{mN}$ load with a Berkovich diamond tip, and calculated by using the Oliver and Pharr method [18]. Every indentation was made in three steps. First, the load was increased linearly from 0 to $12 \mathrm{mN}$ in 5 seconds, then, the load was kept constant at the maximum load during 2 seconds, and finally the tip was unload to $0 \mathrm{mN}$ in 5 seconds. The tip displacement during the second step was used to calculate the creep after software thermal drift correction.

Micro-tribological behavior was studied by friction-wear tests under dry conditions and a relative humidity of $40 \%$ at a room temperature of $22^{\circ} \mathrm{C}$. The methodology to measure simultaneously friction and wear rate has been previously published by one of the authors $[19,20]$. A load of $5 \mathrm{mN}$ was applied on the samples with a conical diamond tip of $2.5 \mu \mathrm{m}$ curvature radius in a reciprocal movement of $5 \mu \mathrm{m}$ length producing an initial mean Hertzian pressure of 13.5 GPa for the hardest hierarchical coating and 4.7 GPa for the uncoated substrate. The whole experiment consisted on 31 cycles to measure friction and 12 scanning of the probe to evaluate the wear. The speed of the probe was set at $1 \mu \mathrm{m} / \mathrm{s}$ in an experiment that takes 712 seconds.

The macro-tribological tests were performed using a tribometer CETR UMT2 with a reciprocating ball-on-plate configuration in relative humidity $(\mathrm{RH})$ of $\sim 46 \%$ at room temperature $\left(\sim 26^{\circ} \mathrm{C}\right)$. The tests were done with a reciprocal sliding movement of $10 \mathrm{~mm}$ stroke length at a frequency of $1 \mathrm{~Hz}$ and, an applied load of $2 \mathrm{~N}$ during 90 min, using a 10 mm alumina ball as counterpart. The initial mean Hertzian pressure were $0.38 \mathrm{GPa}$ for the substrate and 0.55 GPa for the hardest hierarchical coating. After sliding, the cross sectional area of wear scars was measured with a profilometer Veeco Dektak 150. Also, the wear track and the wear debris generated during the macro-tribology test were analyzed by Raman spectroscopy, with a Thermo Scientific DXR confocal Raman microscope. 


\section{Results and discussion}

\subsection{Morphological and Structural Characterization}

Figures 3 and 4 show the cross section of the High HIER sample obtained by FESEM.

These images were used to measure the total thickness of the coatings and the thickness of each layer. The darker zones correspond to WCN films, whereas the clear ones are W and WC layers. The total thickness of the High HIER sample measured was $5300 \pm 220 \mathrm{~nm}$ (Figure 3); from the thickness of each layer (without the $\mathrm{W}$ layer at the interface coating/substrate) we estimated the deposition rates as follows: $17.2 \pm 2.6,15.8 \pm 0.5$ and $18.1 \pm 0.5 \mathrm{~nm} / \mathrm{min}$ for $\mathrm{W}, \mathrm{WCN}$ and WC, respectively. Thus, the total thickness of Low HIER sample was $5500 \pm 220 \mathrm{~nm}$.

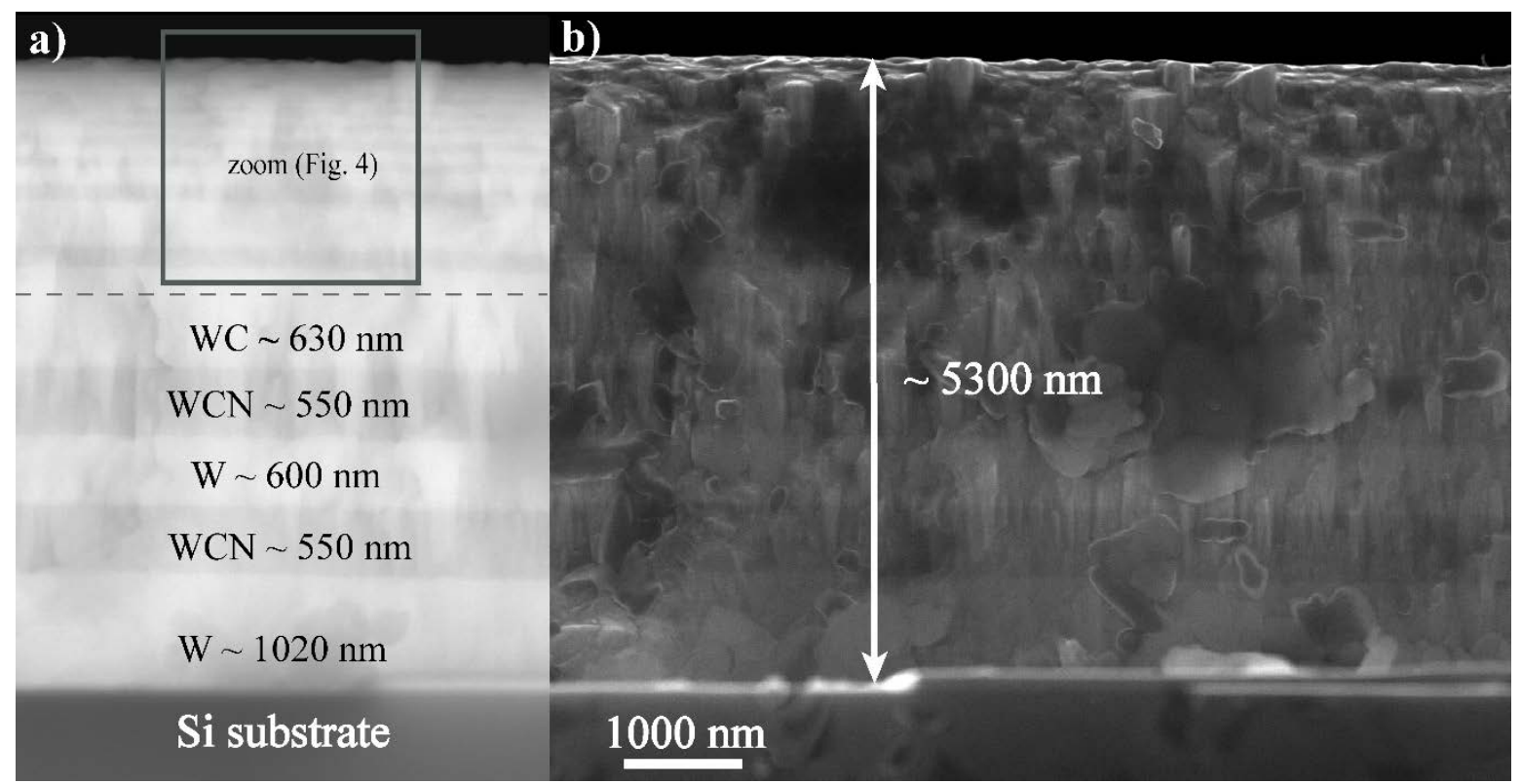

Fig. 3. FESEM images of the cross-section of the High HIER sample. a) Electron backscattering image of the hierarchical configuration of the entire coating; dotted line simulated the interfaces between W and WC. b) Secondary electron image of the total thickness showing the morphology of the coating. 


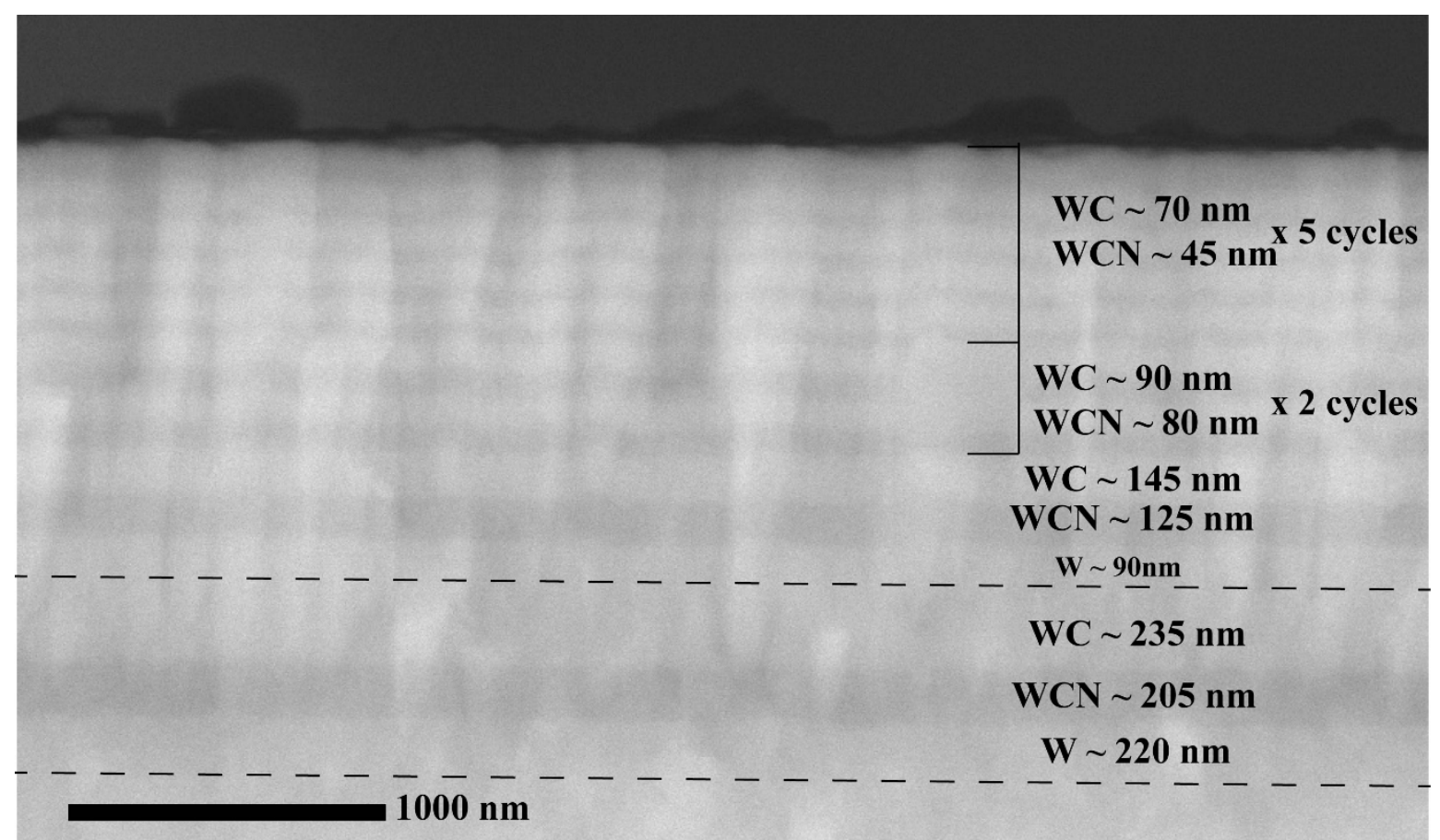

Fig. 4. Electron Backscattering FESEM image from the zoomed area in figure 3 showing in detail the thinnest top layers of High HIER sample. Dotted lines simulated the interfaces between $\mathrm{W}$ and $\mathrm{WC}$

The single-layer WCN sample (Figure 2c) presented a thickness of $1030 \pm 90 \mathrm{~nm}$ deposited in $140 \mathrm{~min}$, resulting in a deposition rate of $7.4 \pm 0.6 \mathrm{~nm} / \mathrm{min}$, which is lower than the expected ( $15.8 \mathrm{~nm} / \mathrm{min}$ ). The difference can be associated to the poisoning of the $\mathrm{W}$ target due to uninterrupted nitrogen exposure in the process, causing a significantly reduction of the sputter rate and therefore in the reduction of the deposition rate [21].

The XRD diffractograms from each coating are shown in Figure 5. The hierarchical coatings present the $\mathrm{WC}_{1-\mathrm{x}}$ fcc cubic structure according to recorded XRD data PDF\#201316. There are no evidences of crystalline phases of W or WCN layers, indicating that they remain in an amorphous phase. The diffraction peak intensity of Low HIER sample is considerably higher than the High HIER sample. This result indicates a lower crystallinity of the multilayer coatings with low period size, which it is in agreement with the results reported by Zhang et al [22] for multilayer systems. The Low HIER sample shows a shift in $2 \theta \approx 0.5^{\circ}$ to lower angles, indicating an increase in the interplanar distance of the coating. This shift can be associated to the typical compressive stresses present in relative thin layer 
coating systems [23, 24]. Such stresses act on the atomic planes perpendicular to the surface substrate, increasing the distance between crystallographic planes parallel to the surface substrate.

Furthermore, other stresses could be generated by the modification of the lattice parameter due to the insertion of atoms of $\mathrm{N}$ into the $\mathrm{WC}_{1-\mathrm{x}}$ lattice; this effect could being stronger at the region near to the transition of the gradual interfaces of WCN or W. Hence, it is possible for the hierarchical samples that there were opposite effects on these stresses: by one side the mismatch between the crystalline $\mathrm{WC}_{1-\mathrm{x}}$ and the amorphous WCN layers produced and incremented stresses at the interphases and, by other side, more gradual changes in the period size in each group of layers produced relaxation effects. In the case of High HIER sample the later effect was dominant according to the lack of shift of its diffraction peak. This result is consistent with the research of X. Zhao et al [25] where a reduction of the radial stress with the increase of the softer layer was found. The grain size for $\mathrm{WC}_{1-\mathrm{x}}$ phase of the hierarchical samples was evaluated using the peak located at $2 \theta \approx$ $61.9^{\circ}$, where the influence of diffractions from WCN or substrate contributes less to the full width at half maximum, by giving values of $4.32 \mathrm{~nm}$ for Low HIER and $3.51 \mathrm{~nm}$ for High HIER samples, which is according with the observed in others research where the reduction of the period size reduces the grain size [22, 24, 25]. 


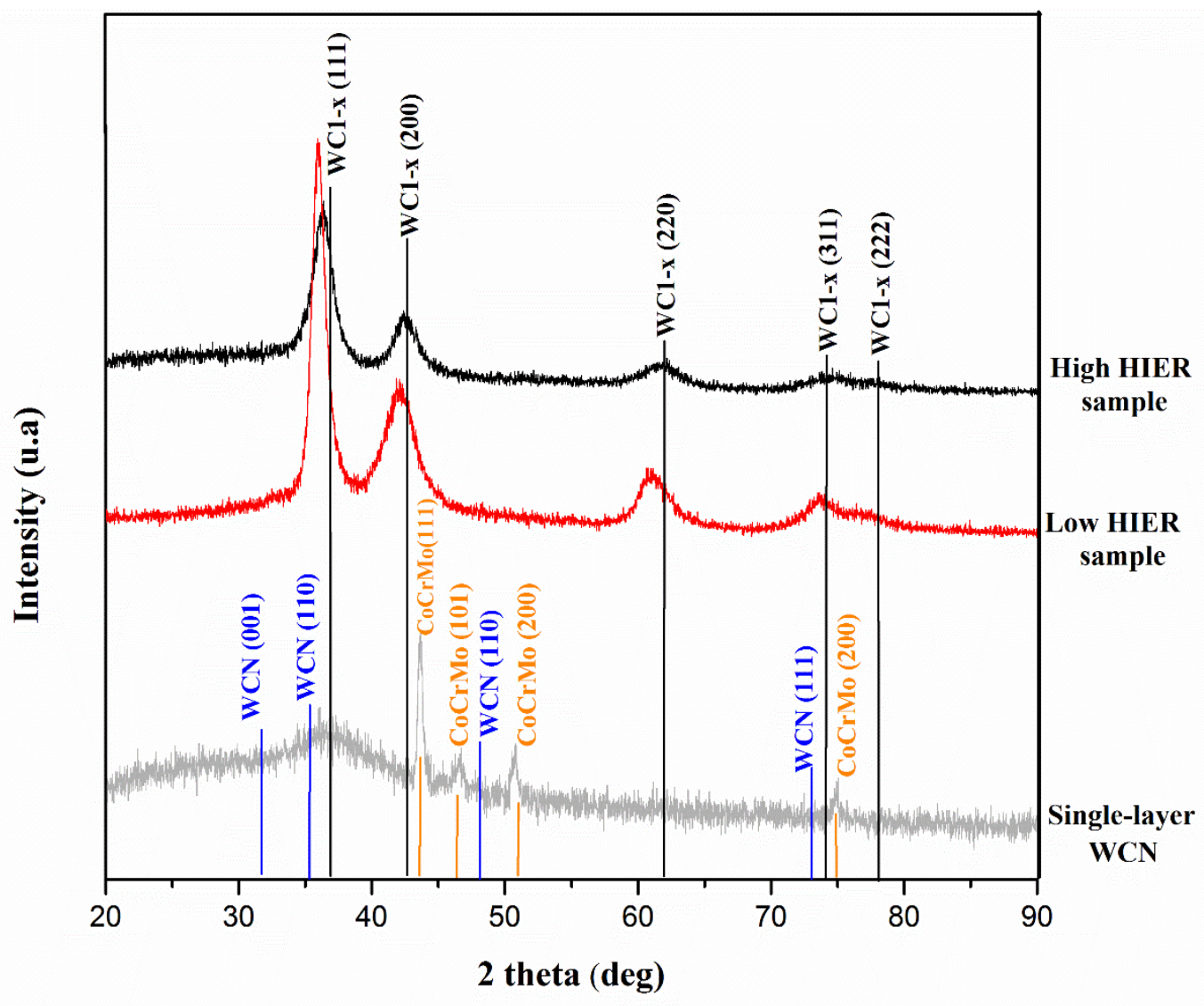

Fig. 5. XRD patterns of two hierarchical samples and single-layer WCN.

XRD analysis of WCN single-layer sample shows only diffraction peaks from the CoCrMo substrate similar to those reported in [2], confirming that the WCN sample is an amorphous phase.

\subsection{Mechanical response by Nanoindentation}

Figure 6a shows load-displacement curves for High HIER, Low HIER samples and the CoCrMo-substrate. To avoid overestimation or underestimation of the mechanical properties in the single-layer WCN sample due to the substrate influence, the penetration depth was kept lower than $10 \%$ of the total film thickness (Figure. 6b). The mechanical response of these samples are summarized in Table 1. High HIER sample shows the highest hardness and reduced elastic modulus followed by the Low HIER and single-layer WCN 
samples, while the substrate present the lowest $\mathrm{H}$ and Er values as expected. The superior mechanical properties obtained for both hierarchical samples can be associated with the architecture design of the multilayer system. The gradual thickness reduction of the High HIER sample produces an increment in hardness and elastic modulus.

For conventional multilayer coatings (without graded configuration) a similar behavior has been observed by K. K. Shih et al [28]. They studied metal and metal-nitride polycrystalline multilayer coatings of $\mathrm{Ti} / \mathrm{TiN}, \mathrm{Hf} / \mathrm{HfN}$ and $\mathrm{W} / \mathrm{WN}$, and observed an increase of hardness as the individual layer thickness decreased, following the Hall-Petch relationship. For the system under study in this work, only the $\mathrm{WC}_{1-\mathrm{x}}$ crystalline phase is observed while the WCN and W crystalline phases are absent indicating that they are present in amorphous form. The possible combination acting as one material can be discarded from the evidence in Figures 3 and 4 where the graded design is clearly observed. The improvement of the mechanical properties for the sample with gradual reduction in thickness (High HIER sample) with respect to abrupt reduction (Low HIER sample) could have an explanation where the geometry of the graded is the dominant, i.e., the periodicity of the material properties and the interlayer thickness controls the mechanical response under indentation test. O. Kolednik et al have shown that interfaces between soft/hard layers can form a shield, which drops the energy of the crack propagation generating toughening mechanisms [29]. Munch et al mentioned that a hierarchical design promotes toughening mechanisms at multiple length scales [30]. Also Xiaoli Zhao et al showed that radial equivalent and shear stresses can be reduced in a multilayer coating, intercalating layers with different mechanical properties like high and low elastic modulus (E) [25]. The radial stress could be reduced by increasing the thickness of the soft (low E) layer. These published reports show that a configuration or design with soft/hard interfaces and, with hierarchical configuration, can generate toughness mechanisms that can improve the resistance to wear in tribology systems. Thus, it is possible that toughing mechanisms were present in our samples with graded function or hierarchical configuration. The improvement of the mechanical properties for High HIER sample can be due to the hierarchical configuration close to the coating surface where its layers have a short period that reduces the grain size and increases the number of interfaces generating a harder 
coating. Also, the soft/hard or amorphous/crystalline interfaces could improve the mechanical properties through the toughness mechanism as referenced above.

The plastic index $H^{3} / E r^{2}$ (see table 1) of the Low HIER sample is slightly higher that High HIER sample indicating a probable better wear resistance [31]. The WC fragility can be reduced by the insertion of the soft layers at the expense of a decreasing in hardness. If the thickness of the soft layers increase, it is expected that stress accumulation decrease, in the same way that in reference [25]. 


\begin{tabular}{lllll}
\hline Samples & $\begin{array}{l}\text { Hardness, } \mathrm{H} \\
(\mathrm{Gpa})\end{array}$ & $\begin{array}{l}\text { Reduced elastic } \\
\text { modulus, } \mathrm{Er} \\
(\mathrm{GPa})\end{array}$ & $H^{3} / E r^{2}$ & $\begin{array}{l}\text { Creep } \\
(\mathrm{nm} / \mathrm{s})\end{array}$ \\
\hline $\begin{array}{l}\text { High HIER } \\
\text { sample }\end{array}$ & $\mathbf{1 9 . 1 \pm 2 . 1}$ & $\mathbf{2 2 3 . 0 \pm \mathbf { 1 . 1 }}$ & $\mathbf{0 . 1 4 0}$ & $\mathbf{1 . 2 6}$ \\
$\begin{array}{l}\text { Low HIER } \\
\text { sample }\end{array}$ & $\mathbf{1 4 . 0 \pm \mathbf { 1 . 5 }}$ & $\mathbf{1 1 5 . 7 \pm 7 . 6}$ & $\mathbf{0 . 2 0 5}$ & $\mathbf{1 . 1 5}$ \\
$\begin{array}{l}\text { Single-layer } \\
\text { WCN }\end{array}$ & $\mathbf{1 1 . 9 6} \pm \mathbf{0 . 7 8}$ & $\mathbf{1 9 1 . 3} \pm \mathbf{6 . 3}$ & $\mathbf{0 . 0 4 7}$ & $\mathbf{0 . 8 2 *}$ \\
$\begin{array}{l}\text { Substrate } \\
\text { CoCrMo }\end{array}$ & $\mathbf{3 . 9 4} \pm \mathbf{0 . 1 2}$ & $\mathbf{4 6 . 0 0 \pm 0 . 5 6}$ & $\mathbf{0 . 0 2 9}$ & $\mathbf{3 . 4 2}$ \\
\hline
\end{tabular}

Table 1. Results obtained by nanoindentation test for the samples under study. * The nanoindentation on the single-layer WCN sample was made with lower indentation load.
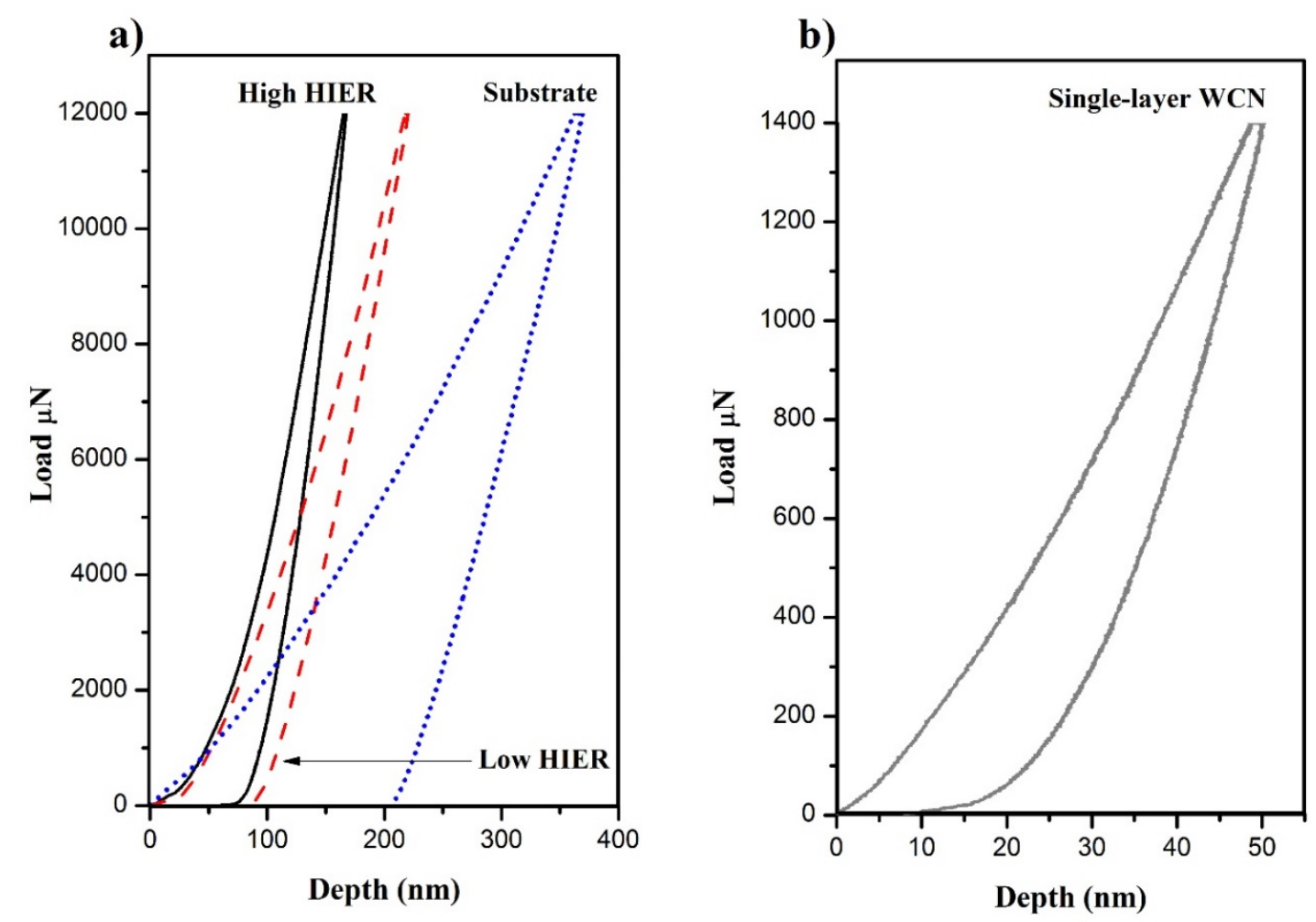

Fig. 6. Load-displacement curves for a) High HIER sample, Low HIER sample and substrate samples, b) Single-layer WCN. 
Creep, the deformation of the coating under a constant stress, has also been determined from nanoindentation measurements. Table 1 shows that High HIER sample has a creep value of $1.26 \mathrm{~nm} / \mathrm{s}$ which is very similar to Low HIER sample $(1.15 \mathrm{~nm} / \mathrm{s}$.). Therefore, there is not a clear tendency of samples to behave differently in regarding to their hierarchical configuration. However, the creep of these hierarchical samples was decreased significantly in comparison to the substrate creep values.

\subsection{Tribological Behavior}

\subsubsection{Microtribology Characterization}

Figure 7 shows the wear evolution maps for the linear reciprocal tests; these maps allow obtaining clear information about the wear evolution with the number of cycles. For the first exploration (row number zero), a surface almost homogeneous with roughness values of $0.5 \mathrm{~nm}$ for the substrate, $1 \mathrm{~nm}$ for the single-layer WCN, $5 \mathrm{~nm}$ for the High HIER and 7 nm for Low HIER samples are observed. For the substrate and single-layer WCN (Figures $7 \mathrm{a}$ and $7 \mathrm{~b}$ ), the wear depth (see bar scale) grows with the number of cycles (Y-axis) to reach a maximum around of the pass number 13 . This maximum wear depth is accompanied with accumulation of material in the borders of the wear track (see the intense red color in the wear maps). After the pass number 13, the indenter tip drags the material accumulated in the borders and produce a filling effect in the wear track reducing the wear depth. This effect is less evident in the hierarchical samples where the High HIER sample (Figure 7d) shows a better response to wear of the indenter tip than Low HIER sample (Figure 7c). Considering the geometrical dimensions of the indenter tip, length of the wear track, applied load and number of cycles, we can estimate that the tip produces a maximum wear rate for High HIER sample of $2.2 \times 10^{-4} \mathrm{~mm}^{3} \mathrm{~N}^{-1} \mathrm{~m}^{-1}$ which is lower than Low HIER sample $\left(4.5 \times 10^{-4} \mathrm{~mm}^{3} \mathrm{~N}^{-1} \mathrm{~m}^{-1}\right)$, Single-layer WCN $\left(1.1 \times 10^{-3} \mathrm{~mm}^{3} \mathrm{~N}^{-1} \mathrm{~m}^{-1}\right)$ and substrate $\left(3.1 \times 10^{-3} \mathrm{~mm}^{3} \mathrm{~N}^{-1} \mathrm{~m}^{-1}\right)$. These results tell us that the plasticity index $\left(\mathrm{H}^{3} / \mathrm{Er}^{2}\right)$, in this case, did not describe completely the wear behavior of the multilayer coatings [28, 29]. It is possible that, at the micro-scale, the roughness and microstructure of the multilayer system have more influence on the wear behavior. 

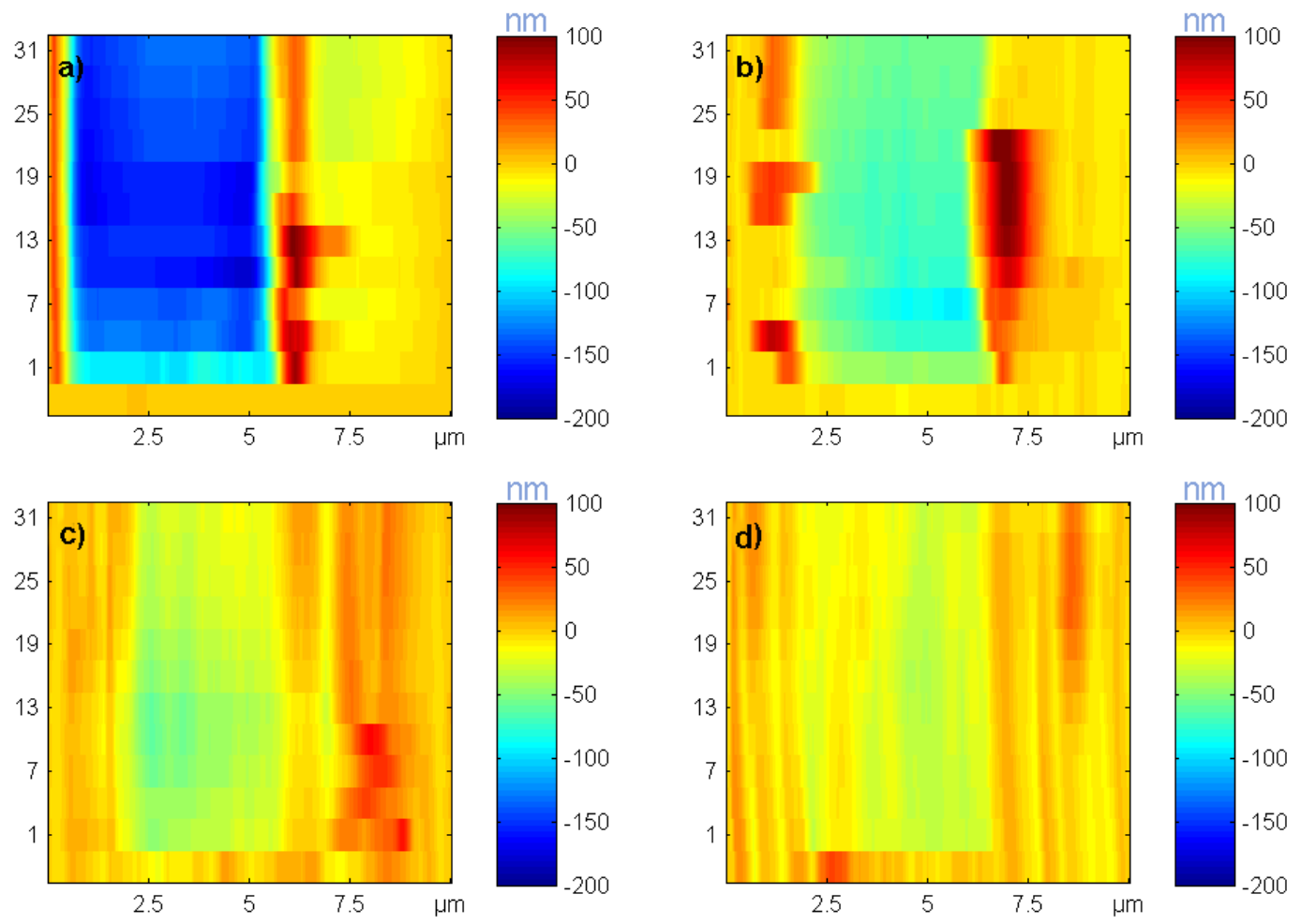

Fig. 7. Wear evolution maps for: a) substrate, b) single-layer, c) Low HIER and d) High HIER samples. Y-axis indicates the number of cycles to produce wear, $\mathrm{X}$-axis is the width of exploration and the bar scale represent the wear depth in nanometers.

The friction coefficient $(\mu)$ as a function of the number of cycles is shown in Figure 8 . The hierarchical samples have a stable $\mu$, exhibiting the High HIER sample the lower friction coefficient of $\sim 0.035$ followed by the Low HIER sample with $\mu \sim 0.06$. Single-layer WCN sample shows a low $\mu(0.05)$ but a poor response to resist wear, and the uncoated substrate shows the higher friction coefficient ( 0.095). The explanation of these results are presented principally as a function of the tip penetration. The results from nanoindentation and the wear evolution maps obtained from the micro-tribology test (see Figure 7) show that the High HIER sample had the lowest tip penetration followed by the Low HIER sample, mainly due to their high hardness. The low penetration indicates less contact area, therefore, this leads to a reduction of the friction force $\left(F_{F}\right)$ and friction coefficient. The higher tip penetration on WCN single layer and substrate than hierarchical coatings, leads 
to increases of the tip-sample contact area and, in the case of substrate, of the friction coefficient, but for WCN single layer, the carbon into the film prevents a high friction. This explanation describes in part the friction coefficient reduction, however tribo-reactions as passivation of dangling bonds by the relative humidity in the environment during the sliding, and transformations of the carbon present into the films, from disordered to ordered, determined by the normal and shear stresses due to the load, also contributes to the low friction coefficient and wear rate as was explained in [34-36].

Our results indicate that, at the micro-scale the coating with hierarchical architecture will show a better wear resistance while maintaining a low $\mu$. Furthermore, architectures with smooth diminution of the layers thickness produce a better tribological behavior during a reciprocal sliding test. Additionally, the mechanical properties are improved.

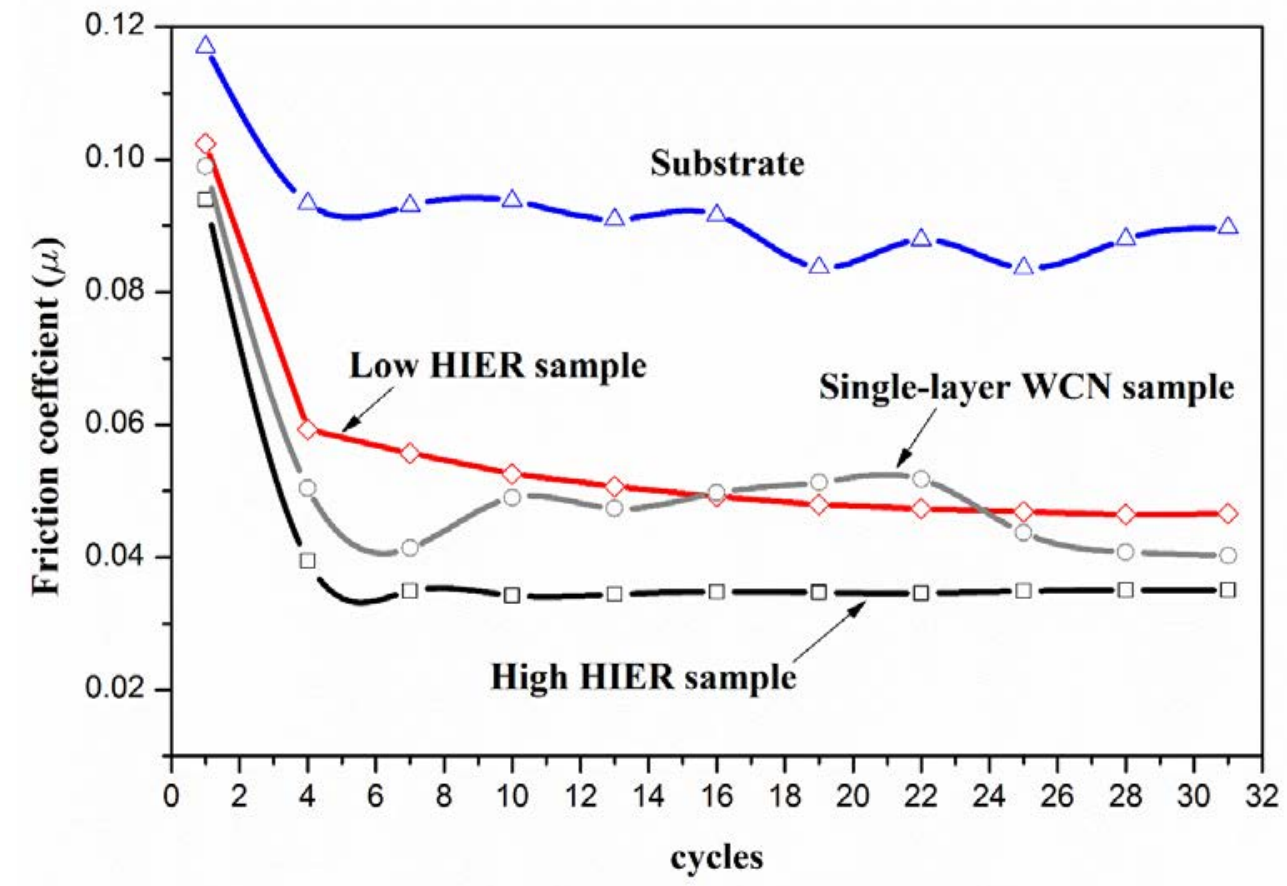

Fig. 8. Friction coefficient behavior of all the samples measured in the microtribology test. 


\subsubsection{Macro-tribology Characterization}

Macro-tribology tests were carried out to study the coating response in another length scale. Tests were performed on High HIER and Low HIER samples, due to their superior performance in the microscale test and on the substrate for comparison.

Figure 9 shows that High HIER sample has more stability and lower $\mu$ (average value of 0.499) than Low HIER sample (average of 0.736). The substrate shows an average $\mu$ of 0.719, while the macro-wear profile of the substrate (Figure 10) gives a mean wear rate of $3.74 \times 10^{-5} \mathrm{~mm}^{3} \mathrm{~N}^{-1} \mathrm{~m}^{-1}$ in $5400 \mathrm{~s}$. Figures 11a and 12a show the typical $10 \mathrm{~mm}$ stroke length wear profiles of the High HIER and Low HIER samples respectively. Red rectangles indicate the zone where there was a measurable wear and the blue rectangles indicate the zones where there was a transferred material and it was not possible to obtain a measurement of the main wear. Figures $11 \mathrm{~b}$ and $12 \mathrm{~b}$ show the cross-sectional profile of the main wear (zone inside of the red rectangles) of High HIER and Low HIER, and in the same way Figures 11c and 12c show the cross-sectional profiles of the transferred material (zone inside of the blue rectangles) after the tribological test. The stroke length wear profile of the High HIER (Figure 11a) sample shows mostly uniform wear along the wear track with transferred material at one side of the track. The wear rate obtained from this sample (Figure 11b) was $1.6 \times 10^{-7} \mathrm{~mm}^{3} \mathrm{~N}^{-1} \mathrm{~m}^{-1}$ which was the lowest of the three samples in macrotribology tests. The stroke length profile of Low HIER sample (Figure 12a) shows a nonuniform wear along the track. Half of the track has a measurable wear (Figure 12b) of 4.6 $\times 10^{-6} \mathrm{~mm}^{3} \mathrm{~N}^{-1} \mathrm{~m}^{-1}$ while the other half shows accumulation of transferred material (Figure 12c). Furthermore in both stroke length profiles it was found the formation of craters, but the ones of the Low HIER were considerably deeper than the craters of the High HIER sample. This difference of craters size suggests that the hierarchical configuration of High HIER sample helps to decrease the formation of defects that produce these craters. 


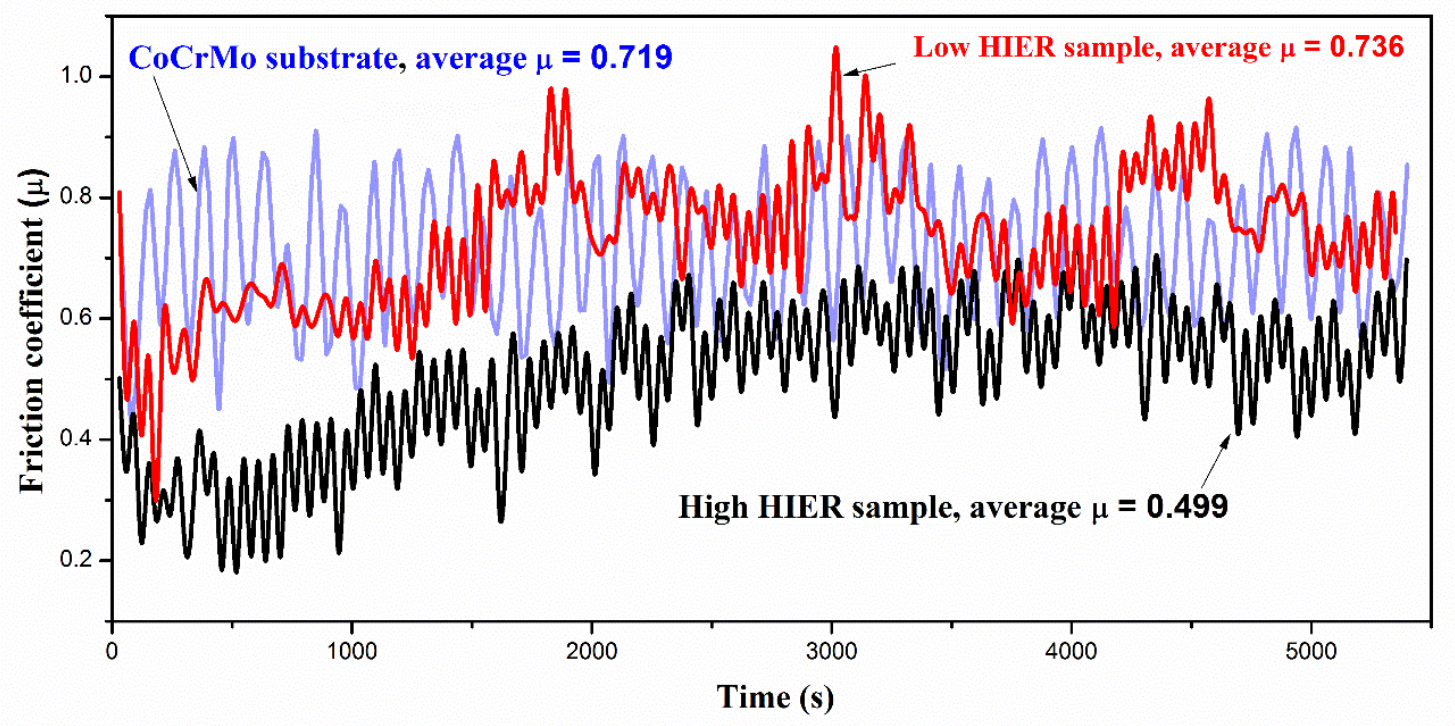

Fig. 9. Friction coefficient of the two graded samples and substrate obtained by the macrotribology test.

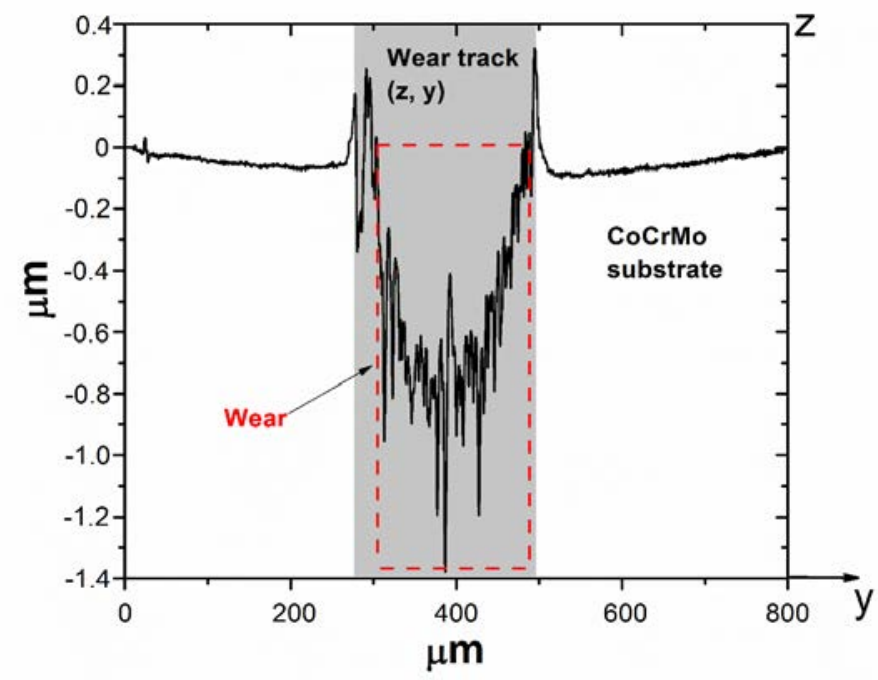

Fig. 10. Typical macro-wear profile of the CoCrMo substrate. 


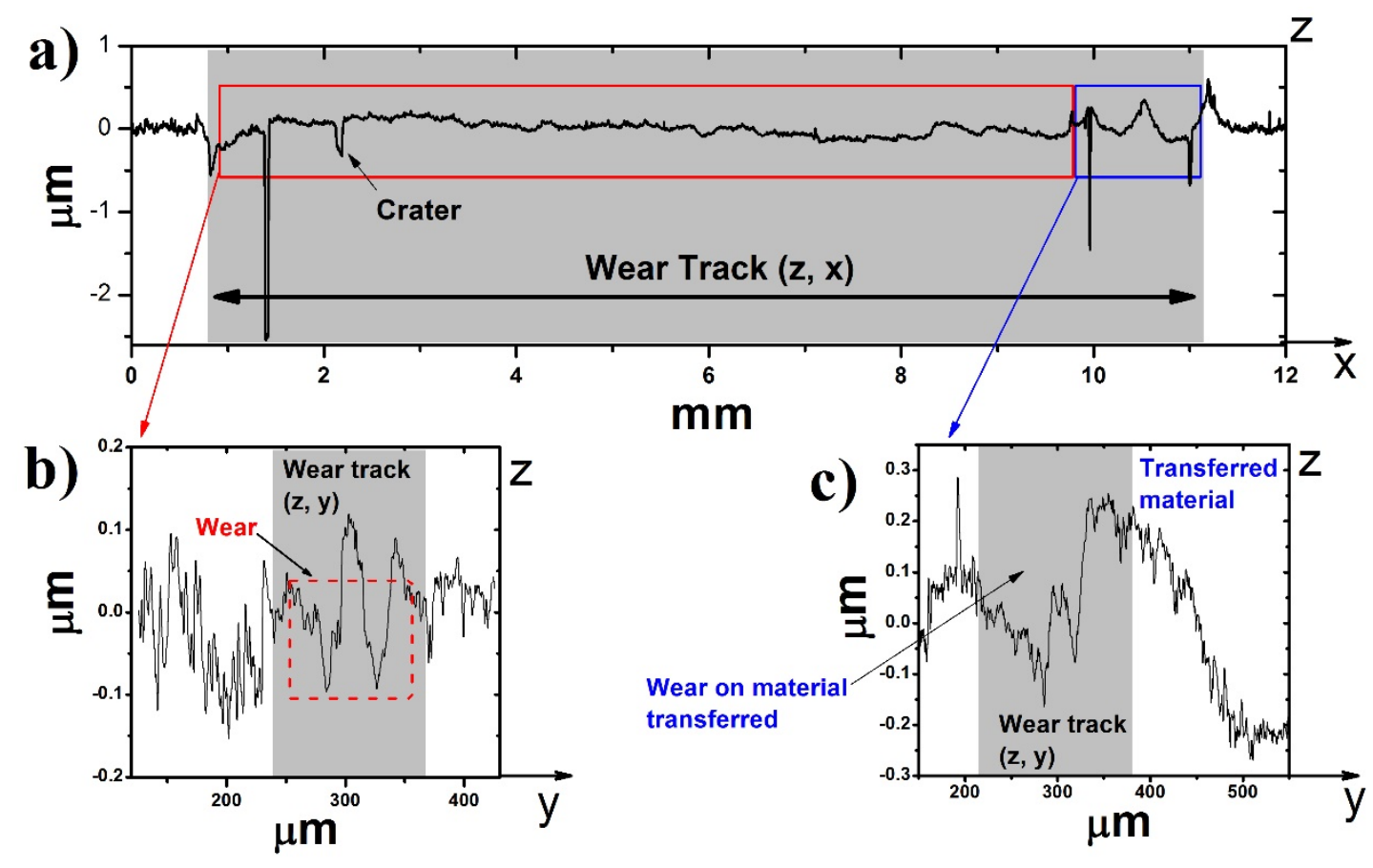

Fig. 11. Typical macro-tribology wear profiles of High HIER sample; a) $10 \mathrm{~mm}$ stroke length profile, the red rectangle denotes the zone where there was a measurable wear; the blue rectangle denotes the zone where there was transferred material; b) cross-sectional profile of the wear track, indicating the wear; c) cross-sectional profile of the wear track, indicating the transferred material. 


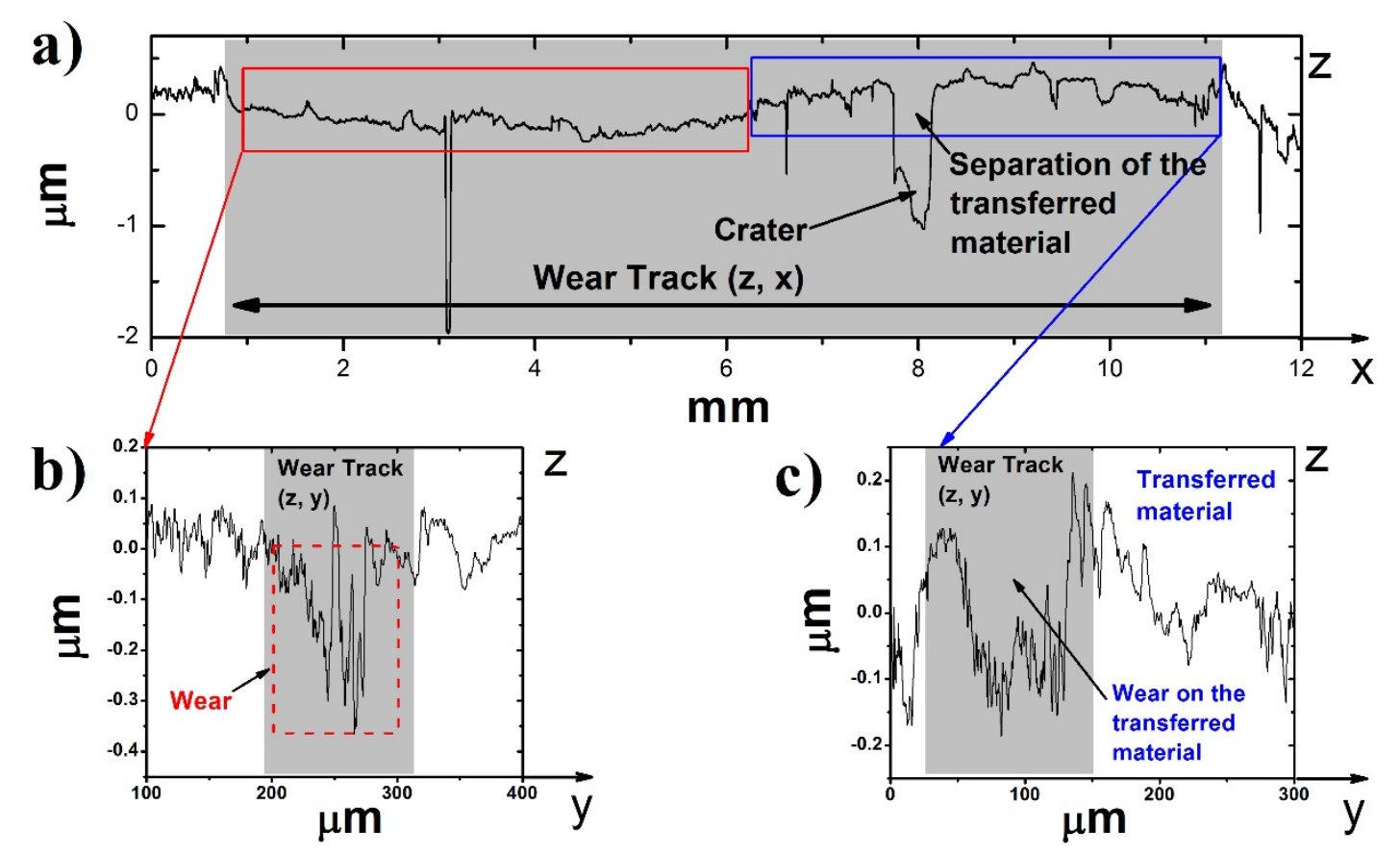

Fig. 12. Typical macro-tribology wear profiles of Low HIER sample; a) 10 mm stroke length profile, the red rectangle denotes the zone where there was a measurable wear; the blue rectangle denotes the zone where there was transferred material; b) cross-sectional profile of the wear track, indicating the wear; c) cross-sectional profile of the wear track, indicating the transferred material.

The lower wear and smaller crater size of the High HIER sample respect to Low HIER sample could be correlated to its high hardness and its capacity to stop the crack propagation. Figures 13a and 13b confirm the presence of transferred material at the edge of the wear tracks and show that the transferred material present cracks, thus, part of the material could be removed and the material that remained could protect against further wear. The high quantity of this transferred material suggests that it helps to reduce the wear rate in both samples during the tribology tests. For this reason, it is important a detailed analysis of this transferred material as we do in the next section. 

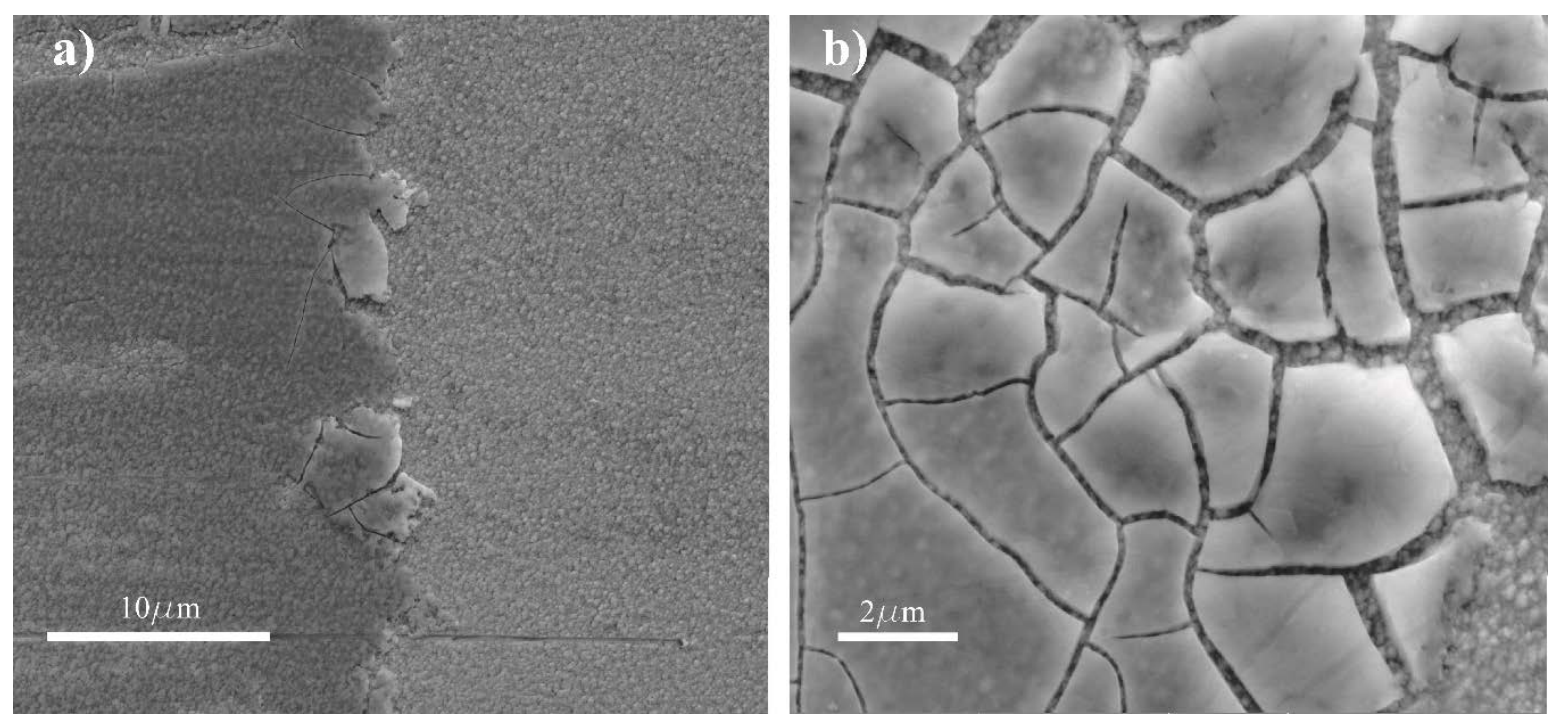

Fig. 13. FESEM images of the extra material produced in the macro-tribology test under. a) High HIER sample. b) Low HIER sample.

\subsubsection{Raman analysis of the wear track}

Figures 14 and 15 show the optical images and the corresponding Raman spectra taken inside and outside the wear tracks from both High HIER and Low HIER samples respectively. The squares in the optical figures (Figures 14a and 15a) correspond to the five areas where the Raman analysis was made. Outside the wear track and far from transferred material (area Z1) we can identify the typical Raman spectra of WC [37] without the influence of others compounds. The analysis of the transferred material (areas Z2-Z4) reveals the formation of graphite-like structures observed at $1580 \mathrm{~cm}^{-1}$ (G-band) and 1357 $\mathrm{cm}^{-1}$ (D-band) [32, 33] in both samples (Figures 14b and 15b). The higher intensity of the G-Band than D-Band also indicates that the transferred material during the sliding is ordered [40], but the passivation mechanism of dangling bonds by the oxygen in environment can not to be discarded due our experimental conditions. Nevertheless, is clear that the introduction of layer containing carbon into the multilayer hierarchical coating leads to improvement in the tribological behavior at the macro-scale as well as micro-scale. This behavior could be due to the tribochemical reactions during the sliding between the 
multilayer and the counterpart, this produces mainly the formation of a graphite tribofilm which has been previously observed [41-43].

a)

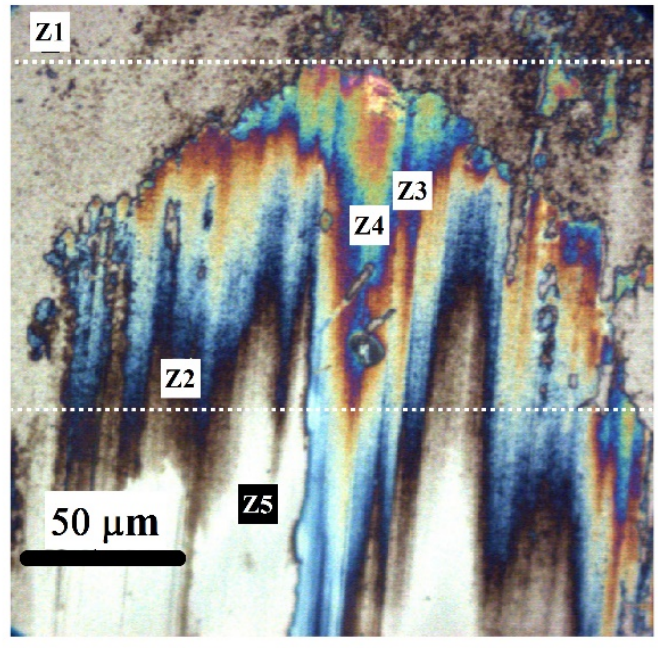

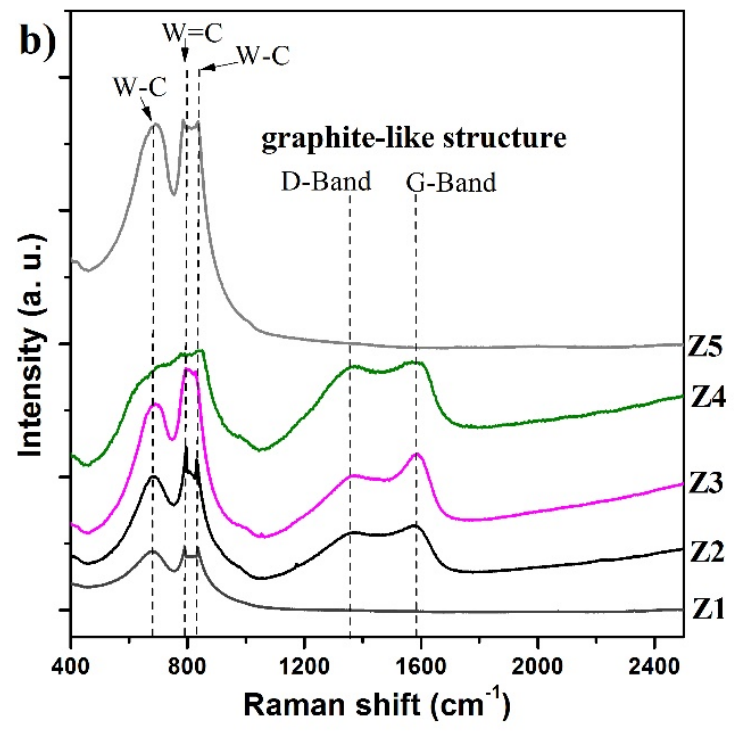

Fig. 14. a) Transferred material of the High HIER sample seen by the Raman optical microscope; the rectangles indicate the points where the Raman analysis was made; b) Raman spectra of the transferred material of High HIER sample. 
a)

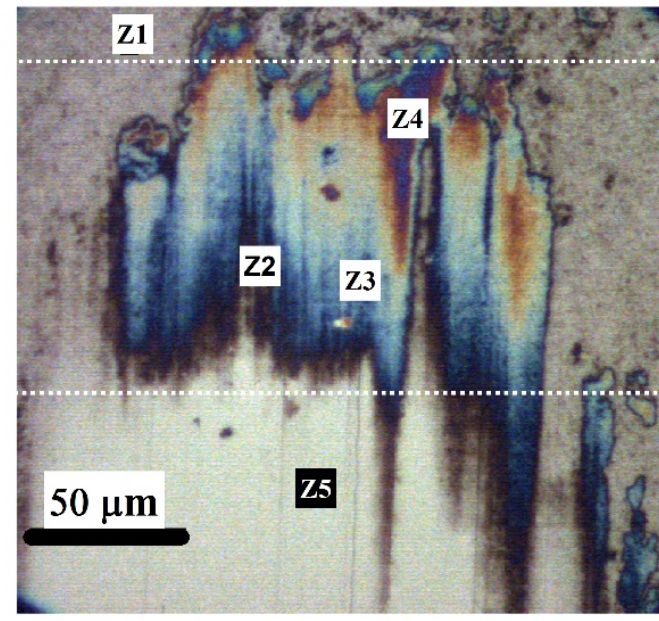

b)

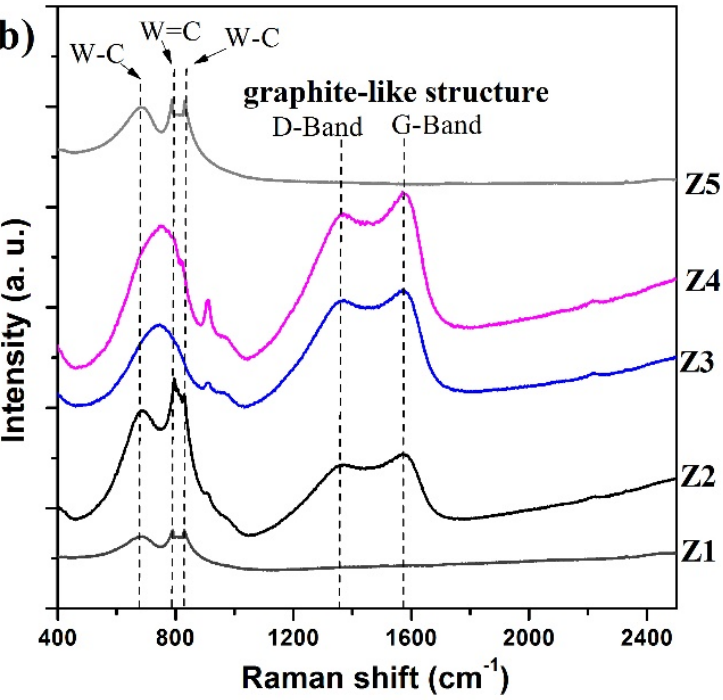

Fig. 15. a) Transferred material of the Low HIER sample seen by the Raman optical microscope; the rectangles indicate the points where the Raman analysis was made; b) Raman spectra of the transferred material of Low HIER sample.

\section{Conclusion}

WC/WCN/W hard coatings with high (High HIER sample) and low (Low HIER sample) hierarchical configurations were structurally, mechanically and tribologically characterized and compared to a WCN single layer coating and to an uncoated CoCrMo substrate.

For High HIER sample, the XRD results have shown that low period size produces lower crystallinity than Low HIER sample, which presented higher crystallinity due to high period size in most of its layers. Furthermore, a shift of $2 \theta \approx 0.5^{\circ}$ in the Low HIER sample was detected due to the dominant effect, being the compressive stress. The lack of this shift in the High HIER sample indicates the dissipation of the stresses, that could be provoked by the more gradual change (or high hierarchical) of the period size in comparison to the Low HIER, where the changes were abrupt. Nanoindentation characterization unveiled that the coating with more interfaces (High HIER sample) was the hardest one with $\mathrm{H}=19.1$ GPa. 
Tribological tests at micro and macro-scale confirm that the High HIER sample presented the lowest wear rate, which can be correlated to its high hierarchical configuration and a possible graphitization at both scales. The tribological test at macro-scale showed that High HIER sample had higher resistance to wear due to its high hardness and smaller craters size in the wear track. The high hierarchical configuration of the High HIER sample could help to dissipate the energy of the crack propagations and avoid bigger craters.

In both hierarchical samples Raman analysis confirmed the formation of graphitic tribofilm that reduced the friction coefficient. Coatings with carbon composition are desirable because they can generate a third body or tribofilm containing graphitic material that can reduce significantly the friction coefficient and wear.

The hierarchical configuration plays an important role in the design of hard coatings for tribological applications. It can help to design a coating for a specific tribological application, through variations of the period sized in groups of multilayers with different mechanical properties.

\section{Acknowledgements}

This research was possible thanks to the economic support of CONACYT-CDTI and CONACYT (REDISYT) under project number 189207 and 254790 respectively. C. D.

Rivera-Tello acknowledge to CONACYT regarding with the scholarship (297914/225114) to study the Ph.D. Esteban Broitman acknowledges the Swedish Government Strategic Research Area in Materials Science on Functional Materials at Linköping University (Faculty Grant SFO-Mat-LiU \# 2009-00971) and the SSF frame program FUNCASE Functional Carbides and Advanced Surface Engineering. F. J. Flores-Ruiz wishes to thank Dr. Martín Yáñez-Limón by the access to XRD system, M. S. Martín A. HernándezLandaverde by the comments about XRD data and to the CONACYT projects CB-201201\#179304, 166286 and LIDTRA Project 123630. 


\section{References}

[1] G. Abadias, a. Michel, C. Tromas, C. Jaouen, and S. N. Dub, "Stress, interfacial effects and mechanical properties of nanoscale multilayered coatings," Surf.

Coatings Technol., vol. 202, no. 4-7, pp. 844-853, Dec. 2007.

[2] B. Alemón, M. Flores, W. Ramírez, J. C. Huegel, and E. Broitman, “Tribocorrosion behavior and ions release of CoCrMo alloy coated with a TiAlVCN/CNx multilayer in simulated body fluid plus bovine serum albumin,” Tribol. Int., vol. 81, pp. 159168, Jan. 2015.

[3] M. Johansson, "Growth of CNx/BN:C multilayer films by magnetron sputtering," Thin Solid Films, vol. 360, no. 1-2, pp. 17-23, Feb. 2000.

[4] G. Ma, G. Lin, S. Gong, X. Liu, G. Sun, and H. Wu, "Mechanical and corrosive characteristics of Ta/TaN multilayer coatings," Vacuum, vol. 89, no. 0, pp. 244-248, 2013.

[5] M. Nordin, M. Larsson, and S. Hogmark, "Mechanical and tribological properties of multilayered PVD TiN/CrN, TiN/MoN, TiN/NbN and TiN/TaN coatings on cemented carbide,” Surf. Coatings Technol., vol. 106, no. 2-3, pp. 234-241, Aug. 1998.

[6] D. J. Srolovitz, S. M. Yalisove, and J. C. Bilello, "Design of Multiscalar Metallic Multilayer Composites for High Strength, High Toughness, and Low CTE Mismatch,” vol. 26, no. July, 1995.

[7] G. S. Was and T. Foecke, “Deformation and fracture in microlaminates,” Thin Solid Films, vol. 286, no. 1-2, pp. 1-31, Sep. 1996.

[8] H.-A. Bahr, H. Balke, T. Fett, I. Hofinger, G. Kirchhoff, D. Munz, A. Neubrand, A. . Semenov, H.-J. Weiss, and Y. . Yang, "Cracks in functionally graded materials," Mater. Sci. Eng. A, vol. 362, no. 1-2, pp. 2-16, Dec. 2003.

[9] J. Xu, J. di Wu, Z. Li, P. Munroe, and Z.-H. Xie, “Mechanical properties of Cralloyed MoSi2-based nanocomposite coatings with a hierarchical structure,” $J$. Alloys Compd., vol. 565, pp. 127-133, Jul. 2013.

[10] Y. Zhang, M.-J. Sun, and D. Zhang, "Designing functionally graded materials with superior load-bearing properties.,” Acta Biomater., vol. 8, no. 3, pp. 1101-8, Mar. 2012.

[11] D. J. Varacalle, L. B. Lundberg, M. G. Jacox, J. R. Hartenstine, W. L. Riggs, H. Herman, and G. A. Bancke, "Fabrication of tungsten coatings and monoliths using the vacuum plasma spray process,” Surf. Coatings Technol., vol. 61, no. 1-3, pp. 7985, Dec. 1993. 
[12] S. S. Mani, J. G. Fleming, J. J. Sniegowski, M. P. de Boer, L. W. Irwin, J. A. Walraven, D. M. Tanner, and D. A. La Van, "Selective W for Coating and Releasing MEMS Devices,” MRS Proc., vol. 605, p. 135, Feb. 2011.

[13] J. Sheward and W. Young, “The deposition of molybdenum and tungsten coatings on gun steel substrates by a plasma assisted CVD technique,” Vacuum, vol. 36, no. 1-3, pp. 37-41, Jan. 1986.

[14] L. Yu, H. Zhao, and J. Xu, "Mechanical, tribological and corrosion performance of WBN composite films deposited by reactive magnetron sputtering,” Appl. Surf. Sci., vol. 315, pp. 380-386, Oct. 2014.

[15] R. Westergård, M. Bromark, M. Larsson, P. Hedenqvist, and S. Hogmark, "Mechanical and tribological characterization of DC magnetron sputtered tantalum nitride thin films,” Surf. Coatings Technol., vol. 97, no. 1-3, pp. 779-784, Dec. 1997.

[16] R. Ospina, D. Escobar, E. Restrepo-Parra, P. J. Arango, and J. F. Jurado, “Substrate temperature influence on W/WCNx bilayers grown by pulsed vacuum arc discharge,” Appl. Surf. Sci., vol. 258, pp. 5100-5104, 2012.

[17] E. Camps, L. Escobar-Alarcón, I. Camps, S. Muhl, and M. Flores, “Tribological characterization of TiCN coatings deposited by two crossed laser ablation plasma beams,” Appl. Phys. A, vol. 110, no. 4, pp. 957-961, Sep. 2012.

[18] W. C. Oliver and G. M. Pharr, "Measurement of hardness and elastic modulus by instrumented indentation: Advances in understanding and refinements to methodology,” J. Mater. Res., vol. 19, no. 01, pp. 3-20, Mar. 2011.

[19] E. Broitman and F. J. Flores-Ruiz, "Novel method for in-situ and simultaneous nanofriction and nanowear characterization of materials,” J. Vac. Sci. Technol. A Vacuum, Surfaces, Film., vol. 33, no. May, p. 043201, 2015.

[20] C. J. Diliegros-Godines, F. J. Flores-Ruiz, R. Castanedo-Pérez, G. Torres-Delgado, F. J. Espinoza-Beltrán, and E. Broitman, "Mechanical and tribological properties of CdO + SnO2 thin films prepared by sol-gel,” J. Sol-Gel Sci. Technol., vol. 74, no. 1, pp. 114-120, 2014.

[21] D. Güttler, B. Abendroth, R. Grötzschel, W. Möller, and D. Depla, “Mechanisms of target poisoning during magnetron sputtering as investigated by real-time in situ analysis and collisional computer simulation,” Appl. Phys. Lett., vol. 85, pp. 61346136, 2004.

[22] G. A. Zhang, Z. G. Wu, M. X. Wang, X. Y. Fan, J. Wang, and P. X. Yan, "Structure evolution and mechanical properties enhancement of Al/AIN multilayer," Appl. Surf. Sci., vol. 253, no. 22, pp. 8835-8840, Sep. 2007. 
[23] T. J. Vink, M. A. J. Somers, J. L. C. Daams, and A. G. Dirks, “Stress, strain, and microstructure of sputter-deposited Mo thin films,” J. Appl. Phys., vol. 70, no. 8, p. 4301, 1991.

[24] L. A. Clevenger, A. Mutscheller, J. M. E. Harper, C. Cabral, and K. Barmak, “The relationship between deposition conditions, the beta to alpha phase transformation, and stress relaxation in tantalum thin films,” J. Appl. Phys., vol. 72, no. 10, p. 4918, 1992.

[25] X. Zhao, Z. Xie, and P. Munroe, "Nanoindentation of hard multilayer coatings: Finite element modelling,” Mater. Sci. Eng. A, vol. 528, no. 3, pp. 1111-1116, Jan. 2011.

[26] M. Flores, S. Muhl, L. Huerta, and E. Andrade, “The influence of the period size on the corrosion and the wear abrasion resistance of TiN/Ti multilayers,” Surf. Coatings Technol., vol. 200, no. 5-6, pp. 1315-1319, Nov. 2005.

[27] K. Abdelouahdi, C. Legrand-Buscema, and P. Aubert, "Microstructure and mechanical properties of nanolayered W/W-C thin films,” J. Mater. Sci., vol. 44, pp. 3408-3412, 2009.

[28] K. K. Shih and D. B. Dove, "Ti/Ti-N Hf/Hf-N and W/W-N multilayer films with high mechanical hardness,” Appl. Phys. Lett., vol. 61, p. 654, 1992.

[29] O. Kolednik, J. Predan, F. D. Fischer, and P. Fratzl, "Bioinspired design criteria for damage-resistant materials with periodically varying microstructure,” Adv. Funct. Mater., vol. 21, no. 19, pp. 3634-3641, 2011.

[30] E. Munch, M. E. Launey, D. H. Alsem, E. Saiz, A. P. Tomsia, and R. O. Ritchie, “Tough, bio-inspired hybrid materials,” Lawrence Berkeley Natl. Lab., 2009.

[31] F. J. Flores-Ruiz, A. Herrera-Gomez, E. Camps, and F. J. Espinoza-Beltrán, “Elastic heterogeneities at the nanoscale in DLC films grown by PLD,” Mater. Res. Express, vol. 2, no. 2, p. 025009, 2015.

[32] J. Guo, H. Wang, F. Meng, X. Liu, and F. Huang, "Tuning the H/E* ratio and $\mathrm{E}^{*}$ of AlN coatings by copper addition,” Surf. Coatings Technol., vol. 228, pp. 68-75, Aug. 2013.

[33] A. Leyland and A. Matthews, “On the significance of the H/E ratio in wear control: a nanocomposite coating approach to optimised tribological behaviour," Wear, vol. 246, no. 1-2, pp. 1-11, Nov. 2000.

[34] T. Kunze, M. Posselt, S. Gemming, G. Seifert, A. R. Konicek, R. W. Carpick, L. Pastewka, and M. Moseler, "Wear, plasticity, and rehybridization in tetrahedral amorphous carbon,” Tribol. Lett., vol. 53, no. 1, pp. 119-126, 2014. 
[35] E. Broitman and L. Hultman, Comprehensive Materials Processing. Elsevier, 2014.

[36] A. R. Konicek, D. S. Grierson, a. V. Sumant, T. a. Friedmann, J. P. Sullivan, P. U. P. a Gilbert, W. G. Sawyer, and R. W. Carpick, "Influence of surface passivation on the friction and wear behavior of ultrananocrystalline diamond and tetrahedral amorphous carbon thin films," Phys. Rev. B - Condens. Matter Mater. Phys., vol. 85, no. 15, pp. 1-13, 2012.

[37] L. C. Agudelo-Morimitsu, J. De La Roche, D. Escobar, R. Ospina, and E. RestrepoParra, "Substrate heating and post-annealing effect on tungsten/tungsten carbide bilayers grown by non-reactive DC magnetron sputtering,” Ceram. Int., vol. 39, no. 7, pp. 7355-7365, 2013.

[38] A. A. U. Voevodin, M. A. Capano, S. J. P. Laube, M. S. Donley, and J. S. Zabinski, "Design of a Ti / TiC / DLC functionally gradient coating based on studies of structural transitions in Ti - C thin films," vol. 298, pp. 107-115, 1997.

[39] K. Adachi and K. Kato, "Tribology of Carbon Nitride Coatings.," in Tribology of Diamond-Like Carbon Films: Fundamentals and Applications., C. Donnet and A. Erdemir, Eds. Springer, 2008, pp. 339-361.

[40] J. C. Sánchez-López, D. Martínez-Martínez, C. López-Cartes, and A. Fernández, "Tribological behaviour of titanium carbide/amorphous carbon nanocomposite coatings: From macro to the micro-scale,” Surf. Coatings Technol., vol. 202, no. 16, pp. 4011-4018, May 2008.

[41] R. Hauert, "An overview on the tribological behavior of diamond-like carbon in technical and medical applications,” Tribol. Int., vol. 37, no. 11-12 SPEC.ISS., pp. 991-1003, 2004.

[42] A. Erdemir and C. Donnet, "Tribology of diamond-like carbon films: recent progress and future prospects,” J. Phys. D Appl. Phys, vol. 39, pp. 311-327, 2006.

[43] C. Charitidis, E. Koumoulos, and D. Dragatogiannis, "Nanotribological Behavior of Carbon Based Thin Films: Friction and Lubricity Mechanisms at the Nanoscale," Lubricants, vol. 1, no. 2, pp. 22-47, 2013. 